\section{A new anchoring technique for accessing the bile duct during direct peroral cholangioscopy using the guide probe of Kautz}
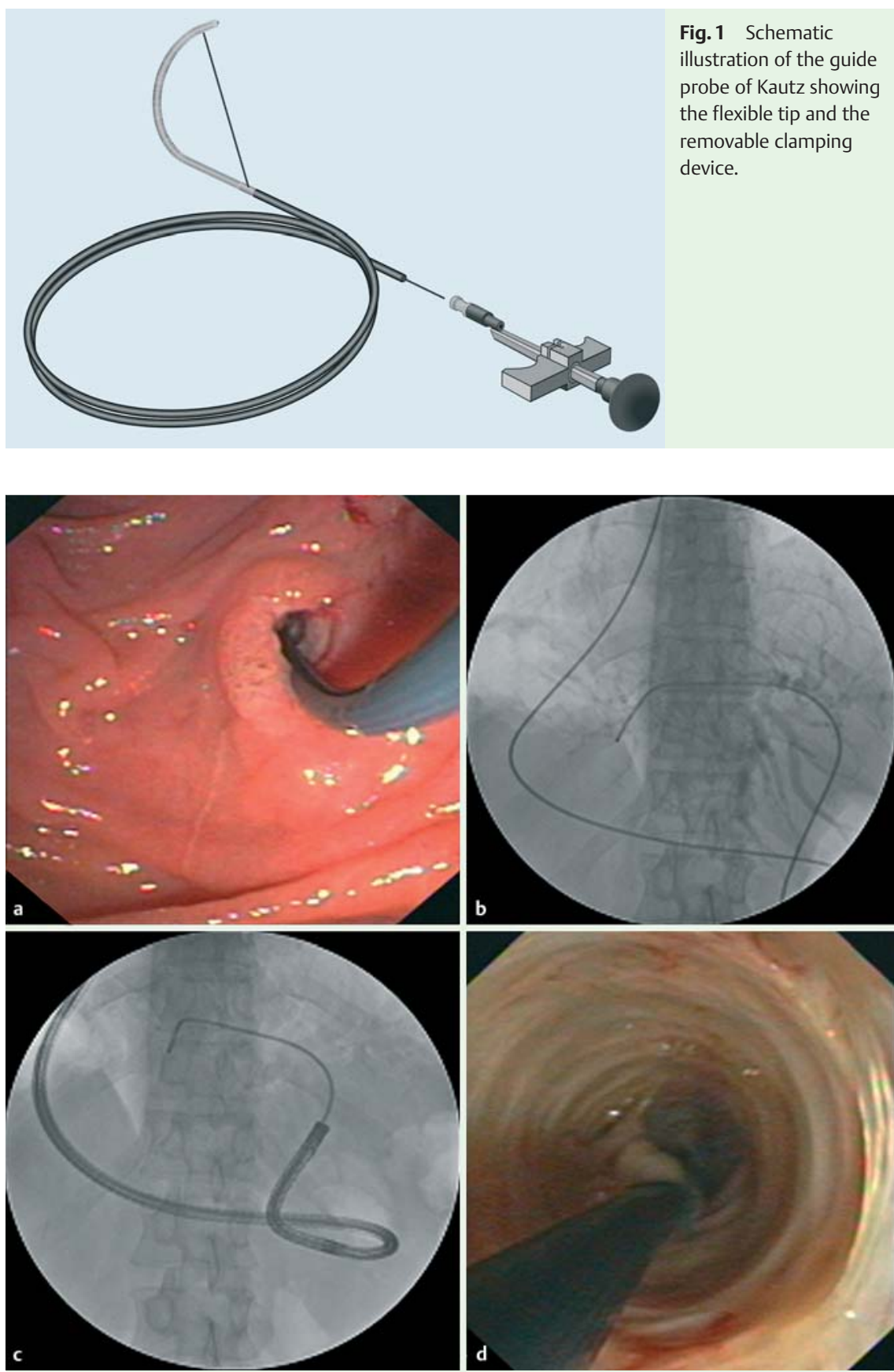

Fig.2 The stages involved in the new anchoring technique for accessing the bile duct using the guide probe of Kautz. a The guide probe is inserted endoscopically into a branch of the intrahepatic bile duct. b Following removal of the duodenoscope, the guide probe is anchored by flexing the tip, as shown in this fluoroscopic image. c, d An ultraslim endoscope can then easily be advanced over the anchored guide probe into the bile duct system as shown $\mathbf{c}$ on fluoroscopy; and $\mathbf{d}$ at endoscopy.
Direct peroral cholangioscopy (POCS) with an ultraslim upper gastrointestinal endoscope has become a very helpful method for direct endoscopic examination and therapeutic intervention in the bile duct system. Several techniques have been reported for achieving endoscopic access to the common bile duct, including placement of an ultrastiff guide wire [1,2] and use of an anchoring balloon [2,3].

We here report on the feasibility of POCS with an alternative technique using a placement device for biliary stents that was originally developed for non-transendoscopic placement of biliary endoprotheses (MTW, Wesel, Germany), which was first described by Kautz in 1983 [4,5]. This device consists of a Teflon-coated metal coil with an atraumatic tip (guide probe), which can be flexed like that of a papillotome. The clamping device is completely removable ( $\bullet$ Fig. 1 ).

After biliary sphincterotomy and balloon dilation of the papilla has been performed, the guide probe is positioned in a branch of the intrahepatic duct through the working channel of a conventional duodenoscope ( Fig.2a,b). The tip is then flexed so that the distal end of the device is anchored within the intrahepatic bile duct system ( Fig. 2 b).

After the duodenoscope has been removed, an ultraslim upper gastrointestinal endoscope (GIF XP180N; Olympus, Tokyo, Japan) is threaded over the guide probe and advanced to the papilla ( $\bullet$ Fig.2c). With the flexed tip of the guide probe held under tension, transpapillary access and advancement of the endoscope into the common bile duct can easily be achieved ( $\bullet$ Fig. 2 d). After the tip is released, the guide probe can be withdrawn from the working channel allowing further diagnostic and therapeutic interventions.

In contrast to balloon-assisted POCS, the guide probe can be kept in the anchored position during exchange of the endoscopes, which therefore allows more stable endoscopic access into the main biliary tract. In conclusion, this alternative technique with a re-useable device may help to further simplify the procedure for endoscopic biliary access, which may therefore enable higher success rates to be achieved in clinical practice.

Endoscopy_UCTN_Code_TTT_1AR_2AB 


\section{T. Beyna * , F. Lenze * K. Hengst,} H. Ullerich

Department of Medicine B, University of Muenster, Muenster, Germany

\section{References}

1 Larghi A, Waxmann I. Endoscopic direct cholangioscopy by using an ultra-slim upper endoscope: a feasibility study. Gastrointest Endosc 2006; 63: 853-857

2 Albert JG, Friedrich-Rust M, Elhendawy $M$ et al. Peroral cholangioscopy for diagnosis and therapy of biliary tract disease using an ul-

* Both authors contributed equally. tra-slim gastroscope. Endoscopy 2011; 43: 1004-1009

3 Moon JH, Ko BM, Choi $\mathrm{HJ}$ et al. Intraductal balloon-guided direct peroral cholangioscopy with an ultraslim upper endoscope (with videos). Gastrointest Endosc 2009; 69: $935-940$

4 Kautz G. Transpapillary bile duct drainage with a large-caliber endoprosthesis. Endoscopy 1983; 15: $312-315$

5 Kautz G, Reers B, Sprakel B et al. More successful and cost effective - the non-transendoscopic method of TPCD. Z Gastroenterol 1993; 31: 149-S153

\section{Bibliography}

DOI http://dx.doi.org/

10.1055/s-0032-1310065

Endoscopy 2012; 44: E372-E373

(C) Georg Thieme Verlag KG

Stuttgart · New York

ISSN 0013-726X

\section{Corresponding author}

T. Beyna, MD

Department of Medicine B

Albert-Schweitzer Campus 1, Gebäude A1

University of Muenster

D-48129 Muenster

Germany

Fax: +49-251-8347576

torsten.beyna@ukmuenster.de 